\title{
THE MODERN ELECTRIC OPHTHALMOSCOPE, ITS DISADVANTAGES AND ADVANTAGES
}

\author{
BY \\ MAJOR R. E. WRIGHT, I.M.S., \\ ACTING SUPERINTENDENT, GOVERNMENT OPHIHALMIC HOSPITAL, MALRAS
}

Ever since the electric ophthalmoscope appeared on the market it has been in constant use in this hospital, and the staff of the institution has seen numerous models spring up and fade away. This process has been too rapid for comfortable smooth working, and the dislocation of routıne work and teaching caused by the stocking of a large variety of instruments for which spares are difficult to obtain, is disconcerting. This fact has so impressed itself on me that I feel compelled to draw the attention of those members of the profession who use the electrical ophthalmoscope to the poor work, lack of enterprize, conservative attitude, and high charges of the firms which turn out these instruments, and perpetuate their disadvantages often in spite of hints and suggestions from those who use them. At the present time we have in use in this hospital five models of electric ophthalmoscopes constructed by five different makers. The Morton-Marple model has always appeared most satisfactory, and I may say at once that without very strong reasons we would not consider other models in ordering new stock. Of the Morton-Marple instruments in stock we have specimens representing five well-known makers. Unfortunately, these makers have introduced modifications from time to time without informing purchasers as to the change. They frequently cease to supply, spares which will fit all the models, and thus place clients at a disadvantage, whilst retailing at a price which should ensure the instrument lasting a life time. Durability will hardly be found to characterize any of the instruments at present procurable, and when such are subject to wear and tear and hardships of a busy dark room they very quickly show up their weak points. It would be much more satisfactory for the purchaser, if makers of these instruments would issue detailed specifications of their models and be responsible for the supply of spare parts for those models up to the average duration of life of the instrument. In considering some of the weak points of the electric opthalmoscope I will confine myself to the MortonMarple type. The chief replacements required for the instruments which we use are, mirrors, lamps, terminals for the flexible cable, and lenses. I presume there is no reason why the electric ophthalmoscope should not be fitted with as good and well-finished a series of lenses mounted in a satisfactory endless groove mechanism 
as was to be obtained in the high-grade reflecting ophthalmoscopes of the Morton type, still, it is rarely that one finds a lens series in an electric ophthalmoscope as well constructed as in some of the older reflecting instruments, particularly those of the Curry and Paxton make.

With reference to the mirrors, it is very seldom that an instrument maker persists for any appreciable time in manufacturing the same size and shape of mirror or mounting it in a constant manner. The result of this is that instruments have frequently to be sent away for mirror replacement. This ought to be quite unnecessary. The owner of an instrument ought to be able to replace his own mirror, and the firm that supplies such instruments ought to see to it that they retain a stock of the particular type of mirror originally supplied with a particular model of machine.

The metal mount on which the mirror is set frequently gives trouble. Some of our most recent instruments obtained from well-known London houses have their mirrors fitted in metal, the chemical decomposition of which produces a green deposit on the mount, this tarnishes the mirror in a very short time and extends down to the small lens between the mirror and the lamp. This is obviously very undesirable, it represents cheap and careless work, and is not to be found in old instruments in which the metal work is good and better finished. The recent models by a well-known ne American firm have a movable clip, which enables one to replace? the mirror with great ease. It appears good, and provided the metal is suitable and the hinge on which it works of really good construction it ought to give satisfaction. The terminal by means of which the instrument is coupled to the flexible cable is very frequently a source of trouble. One has but to handle a modern ophthalmoscope to appreciate this. The most recent model from America which we have in stock, when taken in the hand with the sliding device which regulates the position of the light between the finger and the thumb (and it will not move without finger and thumb control), will be found to have the terminal gripped by third and fourth fingers, and the flex leading to the terminal bent at an acute angle by the heel of the hand On trving now to push up the sleeve which controls the light, instead of the light moving up it goes out altogether as the terminal becomes detached in the grip of the third and fourth fingers. It is quite obvious that the handle is too short, and that a plug-in terminal should not be detached with greater ease than the sliding device moves up and down. The great error in construction is, that the handle is far too short. Instrument makers who turn out these expensive machines would do well to examine and handle a von Fragstein and Kempner's pupil reaction tester, not as sometimes figured without a terminal, but the pattern with 
a $2 \frac{1}{2}$-inch bayonet clutch, metal and vulcanite terminal. This gives a good example of what a comfortable practical handle should be like both in length, thickness, design, and workmanship. In this instrument the terminal is carried well beyond the heel of the hand, and ends in a knob. The bayonet by which the terminal is fixed to the handle is efficient, and the method of attaching the end of the flex to the terminal is exceedingly simple, so that an operator, although not an electrician, can easily mend it should the flex pull out. The sliding device which actuates the tube carrying the lamp should be of such a nature that it can be moved with great ease and delicacy, for when using the electric ophthalmoscope, the thumb and the first finger of the right hand are occupied in rotating the lenses. It would, therefore, be more appropriate if the sliding device could be moved with the second and third fingers. The flex which is supplied with these instruments is often of poorest possible quality. It ought to be of the highest grade obtainable, and each wire should be thoroughly insulated and then encased with its fellow, without twisting, in a common cover. I have mentioned above the undesirability of the ulnar border of the hand kinking the flex at its entry to the terminal at the bottom of the handle. At this point interruption of the circuit most frequently takes place, but short circuiting is quite common elsewhere owing to the poor insulation. A very simple improvement which might be made in most of the instruments is the insertion of a spring contact in the tube into which the lamp is screwed, so that the variation in length of the thread of different lamps may be compensated for. One frequently gets a new stock of lamps and finds that they cannot be screwed home so as to make contact with the conductor which runs up the tube centre. Standardization of the lamp screw threads would save much trouble, and a good pattern filament is badly needed. A filament describing a small circle at right angles to the long axis of the lamp is perhaps best. The range of movement of the lamp too is frequently faulty. It should be capable of being moved to a reasonable extent from a point immediately behind the lens which separates it from the mirror. I will not now elaborate the various points in favour of the electric ophthalmoscope. When the instrument is working, it is so far superior to the reflecting ophthalmoscope as to be almost fool proof. The average individual at the first attempt can see full details of the fundus of the eye when the pupil has been dilated. This cannot be said of its predecessor the reflecting ophthalmoscope. 'It is much more restful to the eyes of the operator and far cooler than the reflecting instrument. Perhaps, however, the point most in its favour is the ease with which minute opacities in the media may be picked up and observed. 